\title{
Characterization of singlet oxygen-accumulating mutants isolated in a screen for altered oxidative stress response in Chlamydomonas reinhardtii
}

\author{
Beat B Fischer ${ }^{1,2^{*}}$, Rik IL Eggen², Krishna K Niyogi ${ }^{1}$
}

\begin{abstract}
Background: When photosynthetic organisms are exposed to harsh environmental conditions such as high light intensities or cold stress, the production of reactive oxygen species like singlet oxygen is stimulated in the chloroplast. In Chlamydomonas reinhardtii singlet oxygen was shown to act as a specific signal inducing the expression of the nuclear glutathione peroxidase gene GPXH/GPX5 during high light stress, but little is known about the cellular mechanisms involved in this response. To investigate components affecting singlet oxygen signaling in C. reinhardtii, a mutant screen was performed.

Results: Mutants with altered GPXH response were isolated from UV-mutagenized cells containing a GPXHarylsulfatase reporter gene construct. Out of 5500 clones tested, no mutant deficient in GPXH induction was isolated, whereas several clones showed constitutive high GPXH expression under normal light conditions. Many of these GPXH overexpressor (gox) mutants exhibited higher resistance to oxidative stress conditions whereas others were sensitive to high light intensities. Interestingly, most gox mutants produced increased singlet oxygen levels correlating with high GPXH expression. Furthermore, different patterns of altered photoprotective parameters like non-photochemical quenching, carotenoid contents and $\alpha$-tocopherol levels were detected in the various gox mutants.

Conclusions: Screening for mutants with altered GPXH expression resulted in the isolation of many gox mutants with increased singlet oxygen production, showing the relevance of controlling the production of this ROS in photosynthetic organisms. Phenotypic characterization of these gox mutants indicated that the mutations might lead to either stimulated triplet chlorophyll and singlet oxygen formation or reduced detoxification of singlet oxygen in the chloroplast. Furthermore, changes in multiple protection mechanisms might be responsible for high singlet oxygen formation and GPXH expression, which could either result from mutations in multiple loci or in a single gene encoding for a global regulator of cellular photoprotection mechanisms.
\end{abstract}

\section{Background}

Light energy is essential for growth of photosynthetic organisms but it can also harm them. Excess light can lead to the increased production of reactive oxygen species (ROS) which can damage cellular components such as lipids, proteins and DNA. Mainly at photosystem (PS) I but also at PSII, electron transfer reactions to molecular oxygen causes the production of superoxide anion radicals $\left(\mathrm{O}_{2}{ }^{-}\right)$, hydrogen peroxide $\left(\mathrm{H}_{2} \mathrm{O}_{2}\right)$ and hydroxyl

\footnotetext{
* Correspondence: beat.fischer@eawag.ch

'Department of Plant and Microbial Biology, University of California, Berkeley, CA 94720-3102 USA

Full list of author information is available at the end of the article
}

radicals $\left(\mathrm{OH}^{\cdot}\right)[1,2]$. At PSII, triplet chlorophyll formation and the interaction with molecular oxygen stimulates the formation of singlet oxygen $\left({ }^{1} \mathrm{O}_{2}\right)$ [3]. Singlet oxygen was shown to contribute significantly to the ROS-induced cellular damage during high light stress [4] and consequently plant and algae have evolved efficient protection mechanisms to prevent the formation of this ROS. Some of these protection mechanisms can be detected as non-photochemical quenching (NPQ) of maximal chlorophyll fluorescence [5]. Short and long term acclimation processes like state transition $(\mathrm{qT})$ or adjustment of PS stoichiometry help to prevent overreduction of the photosynthetic electron transport chain [6].
C Biomed Central

() 2010 Fischer et al; licensee BioMed Central Ltd. This is an Open Access article distributed under the terms of the Creative Commons Attribution License (http://creativecommons.org/licenses/by/2.0), which permits unrestricted use, distribution, and reproduction in any medium, provided the original work is properly cited. 
The energy-dependent quenching (qE) of excess light involves a $\Delta \mathrm{pH}$-induced activation of the xanthophyll cycle in which a violaxanthin de-epoxidase converts violaxanthin $(\mathrm{V})$ into antheraxanthin $(\mathrm{A})$ and zeaxanthin $(\mathrm{Z})$ [7]. Increased levels of these xanthophylls together with the protonation of specific pigment-binding antenna proteins cause a conformational change of PSII into a high quenching state where excess light energy is dissipated as heat [5]. Additionally, zeaxanthin is an efficient ${ }^{1} \mathrm{O}_{2}$ quencher and increased levels of this xanthophyll after exposure to high light conditions might reduce damage to membrane lipids [8,9]. Recently, two LHCSR3 genes have been found to be involved in NPQ in Chlamydomonas reinhardtii indicating that other unidentified components might function in photoprotection and prevention of ${ }^{1} \mathrm{O}_{2}$ formation in photosynthetic organisms [10].

Singlet oxygen can damage the cell but it has also been found to play an important role in retrograde signaling through the specific activation of nuclear genes by plastid signals. Singlet oxygen produced in the chloroplast of the conditional fluorescent $(f l u)$ mutant was shown to stimulate the expression of a set of genes which was different from $\mathrm{H}_{2} \mathrm{O}_{2}$ induced genes [11]. Furthermore, $\mathrm{O}_{2}{ }^{-} / \mathrm{H}_{2} \mathrm{O}_{2}$ exhibited an antagonizing effect on ${ }^{1} \mathrm{O}_{2}$-induced gene expression in flu [12]. In a suppressor screen for the ${ }^{1} \mathrm{O}_{2}$-induced programmed cell death response in $f l u$ mutants, two thylakoid-localized proteins, EXECUTER1 (EX1) and EXECUTER2 (EX2), were identified which are involved in the regulation of the ${ }^{1} \mathrm{O}_{2}$-mediated genetic response $[13,14]$. In C. reinhardtii, the response to ${ }^{1} \mathrm{O}_{2}$ has been studied using either specific exogenous photosensitizers like rose bengal (RB) or neutral red (NR) [15] or in strains lacking some ${ }^{1} \mathrm{O}_{2}$ protective mechanisms like the xanthophylldeficient mutant npq1 lor1 [16]. As found in A. thaliana, the response of the Chlamydomonas HSP7OA gene to ${ }^{1} \mathrm{O}_{2}$ could be distinguished from the response to $\mathrm{H}_{2} \mathrm{O}_{2}$ by different reporter constructs and was attributed to separate promoter regions [17]. Furthermore, the glutathione peroxidase homologous gene GPXH/GPX5 of C. reinhardtii was strongly induced by ${ }^{1} \mathrm{O}_{2}$ but to a much lower extent by other ROS [18]. During high light stress, GPXH expression is strongly induced by ${ }^{1} \mathrm{O}_{2}$ by transcriptional activation $[19,20]$ and various regulatory elements in the promoter were required for induction by ${ }^{1} \mathrm{O}_{2}$ [21]. The GPXH protein is predicted to be dualtargeted to the cytoplasm and the chloroplast, and its peroxidase activity with plastidial thioredoxin indicates a role in oxidative stress response of the chloroplast [21].

Even though ${ }^{1} \mathrm{O}_{2}$ can function as a signal to activate nuclear gene expression, our knowledge of how the formation of ${ }^{1} \mathrm{O}_{2}$ is controlled in photosynthetic organisms and which components are involved in the signal transduction from the plastid to the nucleus is still far from complete. Membrane lipids are primary targets of ${ }^{1} \mathrm{O}_{2}$, and oxidized fatty acids could function as signaling intermediates $[22,23]$. However, experiments with carotenoid-depleted cultures indicated that in $C$. reinhardtii the sensor for ${ }^{1} \mathrm{O}_{2}$ is not a lipophilic compound in the thylakoid membrane but probably is located in the aqueous phase of the chloroplast [24]. In an effort to identify components that affect the ${ }^{1} \mathrm{O}_{2}$ induced genetic response in $C$. reinhardtii, we performed a mutant screen using a ${ }^{1} \mathrm{O}_{2}$-specific GPXH reporter construct. Mutants with altered GPXH expression were isolated and characterized genetically and physiologically.

\section{Results}

\section{Isolation of mutants with altered GPXH expression}

The expression of the GPXH gene is strongly induced by the increased production of ${ }^{1} \mathrm{O}_{2}$ in the chloroplast. To identify components affecting ${ }^{1} \mathrm{O}_{2}$-induced gene expression in $C$. reinhardtii, a mutant screen was performed using the GPXH-arylsulfatase (GPXH-ARS) reporter gene construct pYSn1 to search for clones with altered GPXH response [21]. The wild-type strain $4 \mathrm{~A}^{+}$transformed with pYSn1 was UV-mutagenized and colonies were grown on TAP plates in the dark. Then, a total number of 5500 clones were analyzed for their GPXH$A R S$ expression under medium light (ML) condition of $80 \mu \mathrm{mol}$ photons $\mathrm{m}^{-2} \mathrm{~s}^{-1}$ in the presence or absence of $1 \mu \mathrm{M}$ NR. Average GPXH-ARS expression was induced $6.0 \pm 2.0$ fold by NR treatment. A cutoff of 2.5 -fold induction by NR and 2.2 fold higher expression was used to select for clones with reduced induction or increased basal expression, resulting in 22 GPXH-ARS induction deficient (gid) and 41 GPXH-ARS overexpressor (gox) mutants (Figure 1A). However, after retesting these clones, only six gid and 32 gox mutants could be confirmed.

Altered response of the reporter enzyme in $4 \mathrm{~A}^{+}$pYSn1 can result from mutations affecting the cellular ARS activity, the production of ${ }^{1} \mathrm{O}_{2}$ or the signal transduction of ${ }^{1} \mathrm{O}_{2}$-induced gene expression. To identify the first class of mutants, the induction of the endogenous GPXH gene was measured in the six gid mutants exposed to NR. Unfortunately, all gid mutants retained full induction of the GPXH wild-type gene (data not shown). For the 32 gox mutants, a secondary screen was performed to reduce the number of strains for GPXH expression analysis. Based on the knowledge that GPXH overexpression increases the resistance of $C$. reinhardtii to chemicals enhancing ROS production [25], the mutants were exposed to the ${ }^{1} \mathrm{O}_{2}$-producing photosensitizers $\mathrm{RB}$ and $\mathrm{NR}$ at ML conditions or the $\mathrm{O}_{2}{ }^{-}$-producing chemicals metronidazole (MZ) and methyl viologen (MV) and the organic tert-butylhydroperoxide $(\mathrm{t}-\mathrm{BOOH})$ under low light intensity (LL, $15 \mu \mathrm{mol}$ photons $\mathrm{m}^{-2} \mathrm{~s}^{-1}$ ). One group 


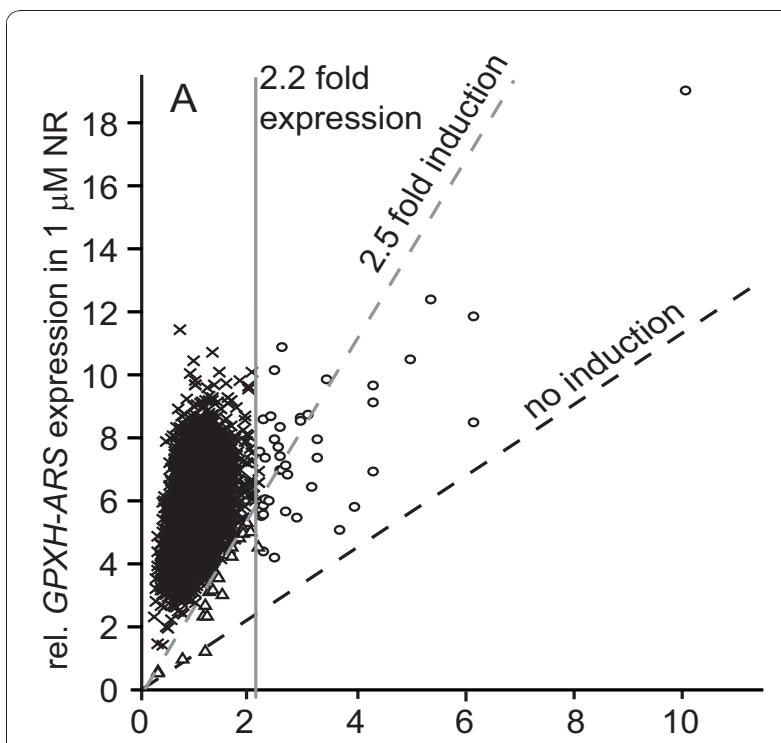

rel. GPXH-ARS expression control

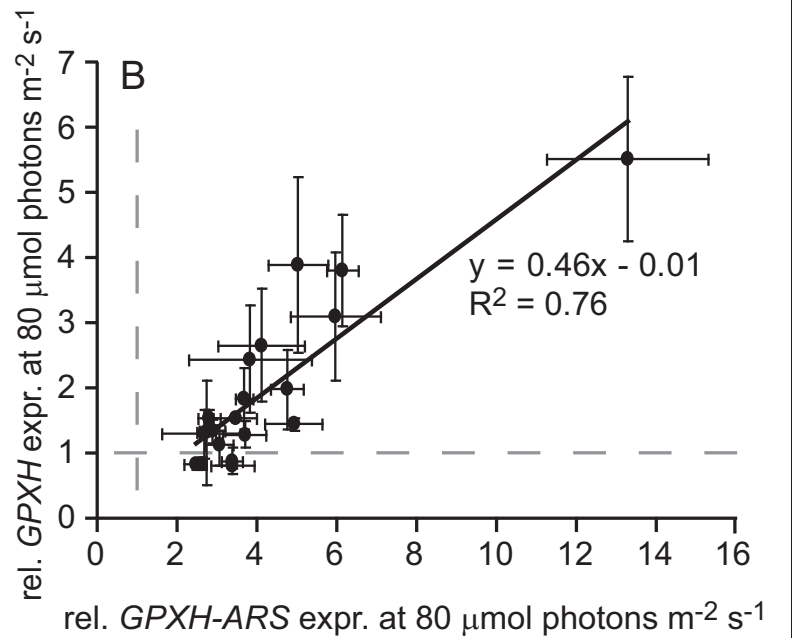

Figure 1 GPXH-ARS expression in the screened mutants. A. 5500 clones were analyzed for the expression of the GPXH-ARS reporter construct under control or $2 \mu \mathrm{M}$ NR-treated conditions. Clones with reduced induction by NR ( $<2.5$ fold, triangles) or increased basal expression under control condition (> 2.2 fold expression, circles) were selected for further analysis. B. Correlation of GPXH expression (wild-type gene) with the expression of the GPXH-ARS reporter construct in 20 GPXH overexpression (gox) mutants. Average expression was calculated from three independent experiments $( \pm$ $\mathrm{SE}$ ) and normalized to wild-type levels (grey dashed lines).

of mutants with 13 members was more resistant to $\mathrm{t}$ - $\mathrm{BOOH}$ compared to wild-type, and many but not all of these mutants were also resistant to NR and RB (Table 1). Furthermore, all strains were tested for their tolerance to high light intensities (HL, $500 \mu \mathrm{mol}$ photons $\mathrm{m}^{-2} \mathrm{~s}^{-1}$ ) resulting in the identification of $11 \mathrm{HL}$-sensitive clones. This phenotype was often combined with sensitivity to RB, NR, MZ or MV. A third group of mutants (12 clones) showed no or only very weak changes in
Table 1 Tolerance of gox mutants to various oxidative stress conditions

\begin{tabular}{lcccccc}
\hline Mutant & HL & t-BOOH & NR & RB & MZ & MV \\
\hline $22 \mathrm{D} 2$ & $\mathrm{~S}$ & $\mathrm{n}$ & $\mathrm{n}$ & $\mathrm{n}$ & $\mathrm{S}$ & $\mathrm{s}$ \\
$22 \mathrm{D} 1$ & $\mathrm{~S}$ & $\mathrm{n}$ & $\mathrm{n}$ & $\mathrm{s}$ & $\mathrm{S}$ & $\mathrm{n}$ \\
$21 \mathrm{E} 2$ & $\mathrm{~S}$ & $\mathrm{n}$ & $\mathrm{n}$ & $\mathrm{n}$ & $\mathrm{S}$ & $\mathrm{n}$ \\
$15 \mathrm{~B} 10$ & $\mathrm{~S}$ & $\mathrm{n}$ & $\mathrm{n}$ & $\mathrm{n}$ & $\mathrm{S}$ & $\mathrm{n}$ \\
$18 \mathrm{C} 2$ & $\mathrm{~S}$ & $\mathrm{n}$ & $\mathrm{n}$ & $\mathrm{s}$ & $\mathrm{n}$ & $\mathrm{n}$ \\
$18 \mathrm{~F} 6$ & $\mathrm{~S}$ & $\mathrm{n}$ & $\mathrm{n}$ & $\mathrm{n}$ & $\mathrm{n}$ & $\mathrm{n}$ \\
$14 \mathrm{H} 8$ & $\mathrm{~S}$ & $\mathrm{n}$ & $\mathrm{n}$ & $\mathrm{n}$ & $\mathrm{r}$ & $\mathrm{n}$ \\
$18 \mathrm{G} 9$ & $\mathrm{~S}$ & $\mathrm{R}$ & $\mathrm{r}$ & $\mathrm{n}$ & $\mathrm{r}$ & $\mathrm{R}$ \\
$21 \mathrm{~B} 4$ & $\mathrm{~S}$ & $\mathrm{R}$ & $\mathrm{S}$ & $\mathrm{n}$ & $\mathrm{S}$ & $\mathrm{n}$ \\
$26 \mathrm{D} 5$ & $\mathrm{~S}$ & $\mathrm{r}$ & $\mathrm{n}$ & $\mathrm{n}$ & $\mathrm{n}$ & $\mathrm{n}$ \\
$14 \mathrm{~A} 9$ & $\mathrm{~S}$ & $\mathrm{r}$ & $\mathrm{n}$ & $\mathrm{r}$ & $\mathrm{n}$ & $\mathrm{n}$ \\
$14 \mathrm{~B} 5$ & $\mathrm{n}$ & $\mathrm{R}$ & $\mathrm{r}$ & $\mathrm{r}$ & $\mathrm{n}$ & $\mathrm{r}$ \\
$14 \mathrm{C} 11$ & $\mathrm{n}$ & $\mathrm{r}$ & $\mathrm{r}$ & $\mathrm{r}$ & $\mathrm{n}$ & $\mathrm{n}$ \\
$15 \mathrm{H} 8$ & $\mathrm{n}$ & $\mathrm{R}$ & $\mathrm{R}$ & $\mathrm{r}$ & $\mathrm{n}$ & $\mathrm{n}$ \\
$35 \mathrm{H} 11$ & $\mathrm{n}$ & $\mathrm{R}$ & $\mathrm{R}$ & $\mathrm{r}$ & $\mathrm{n}$ & $\mathrm{n}$ \\
$20 \mathrm{H} 4$ & $\mathrm{n}$ & $\mathrm{R}$ & $\mathrm{r}$ & $\mathrm{r}$ & $\mathrm{n}$ & $\mathrm{n}$ \\
$18 \mathrm{~B} 11$ & $\mathrm{n}$ & $\mathrm{r}$ & $\mathrm{R}$ & $\mathrm{n}$ & $\mathrm{n}$ & $\mathrm{n}$ \\
$13 \mathrm{D} 3$ & $\mathrm{n}$ & $\mathrm{R}$ & $\mathrm{n}$ & $\mathrm{n}$ & $\mathrm{n}$ & $\mathrm{n}$ \\
$13 \mathrm{H} 11$ & $\mathrm{n}$ & $\mathrm{R}$ & $\mathrm{n}$ & $\mathrm{s}$ & $\mathrm{n}$ & $\mathrm{n}$ \\
$19 \mathrm{H} 4$ & $\mathrm{n}$ & $\mathrm{R}$ & $\mathrm{S}$ & $\mathrm{s}$ & $\mathrm{S}$ & $\mathrm{r}$ \\
\hline
\end{tabular}

Abbreviations: $\mathrm{HL}$ : high light of $500 \mu \mathrm{mol}$ photons $\mathrm{m}^{-2} \mathrm{~s}^{-1} \mathrm{PAR}, \mathrm{t}-\mathrm{BOOH}$ : tertbutylhydroperoxide, NR: neutral red, RB: rose bengal, MZ: metronidazole, MV: methyl viologen. Tolerance was classified in five different categories compared to the wild-type strain: S: very sensitive, s: sensitive, n: no difference from wild-type, $\mathrm{r}$ : resistant, R: very resistant. Mutants could be divided into three different groups: $\mathrm{HL}$ sensitive mutants, $\mathrm{t}-\mathrm{BOOH}$ resistant mutants and mutants with no or only minor changes in tolerance (not shown).

tolerance to oxidative stress. Since for this subset of mutants a relatively low GPXH-ARS overexpression was determined, they were excluded from further analysis.

The remaining 20 mutants, being either HL-sensitive and/or $\mathrm{t}-\mathrm{BOOH}$ resistant, were then tested for the expression of the endogenous GPXH wild-type gene by qPCR. A significantly $(\mathrm{P}<0.05)$ stimulated expression compared to the corresponding wild-type strain could be detected in seven clones ranging from 1.4- to 5.5-fold overexpression (Additional file 1). Even though there was a clear correlation $\left(\mathrm{R}^{2}=0.76\right)$ between GPXH expression and the expression of the reporter construct, all 20 mutants had a stronger overexpression of GPXH-ARS measured by enzyme activity than GPXH expression determined by qPCR, which might be the consequence of individual mRNA or the reporter enzyme stability (Figure 1B).

High doses of UV radiation as applied in this experiment induce multiple point mutations in the genome. To analyze whether defects in multiple genes might be responsible for the phenotype, we performed tetrad analysis of selected gox mutants by crossing them back to the strain $4 \mathrm{~A}^{-}$pYS1. Twelve independent tetrads were tested for segregation of high GPXH-ARS expression in 
each mutant. A clear 2:2 segregation of the wild-type and mutant phenotypes was found in strains $35 \mathrm{H} 11$ and 18F6 (Figure 2), indicating that mutations in a single nuclear gene is responsible for the increased GPXH expression in each case. The same was true for 21B4 except for one tetrad where one high, two medium and one low expressing progeny were found, suggesting that two closely linked mutations might be responsible for the high ARS activity phenotype. No consistent 2:2 segregation was found in backcrosses of strain 22D1 and 14A9. Whereas for 22D1 at least six tetrads resulted in either 3:1 or 1:2:1 segregations, for 14A9 the pattern of three tetrads differed from standard single allele segregation.

\section{GPXH overexpression in gox mutants due to increased singlet oxygen production}

Stimulated GPXH expression might either be due to a stimulated production of ${ }^{1} \mathrm{O}_{2}$ or a constitutively active signaling pathway under LL condition. Sensitivity to HL intensity of several mutants indicates that the former might be the reason for high GPXH expression in some of the gox mutants. The formation of ${ }^{1} \mathrm{O}_{2}$ was therefore measured with the fluorescent dye singlet oxygen sensor green (SOSG) allowing the specific quantification of ${ }^{1} \mathrm{O}_{2}$ [26]. In order to detect significant amounts of ${ }^{1} \mathrm{O}_{2}$ with the membrane impermeable SOSG in the wild-type strain, the cells had to be broken by freezing, and exposed to HL intensity $\left(500 \mu \mathrm{mol}\right.$ photons $\mathrm{m}^{-2} \mathrm{~s}^{-1}$ ) for a period of $15 \mathrm{~min}$. Increased ${ }^{1} \mathrm{O}_{2}$ formation compared to wild-type (at least 1.8 fold) was detected in all but one of the HL-sensitive mutants (Figure 3 Additional file 2). Surprisingly, several

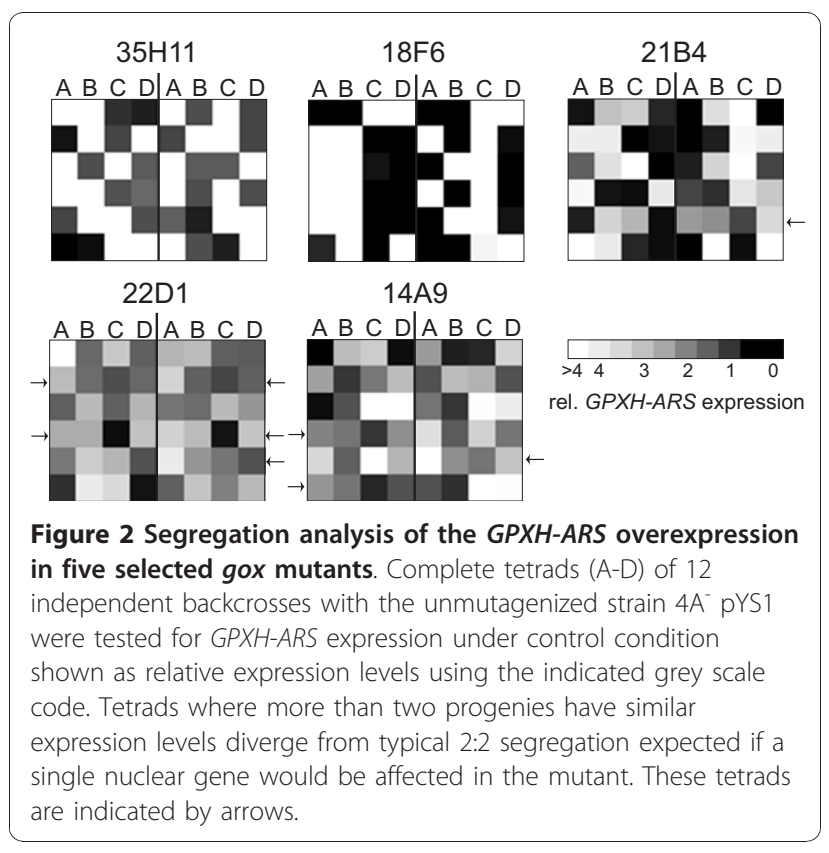

mutants with normal resistance to HL also showed a stimulated ${ }^{1} \mathrm{O}_{2}$ production even though the difference to wild-type was not always significant $(\mathrm{P}<0.05)$.

Comparing ${ }^{1} \mathrm{O}_{2}$ formation with GPXH overexpression in gox mutants, no direct correlation $\left(\mathrm{R}^{2}=0.04\right)$ between the two parameters could be found (Figure $3 \mathrm{~A})$. However, since the formation of ${ }^{1} \mathrm{O}_{2}$ is a light intensity-dependent photoreaction and GPXH expression and ${ }^{1} \mathrm{O}_{2}$ formation were quantified at different light intensities ( 80 and $500 \mu \mathrm{mol}$ photons $\mathrm{m}^{-2} \mathrm{~s}^{-1}$ ), it is difficult to directly compare these parameters. We therefore measured GPXH expression in all 20 gox mutants at the highest possible light intensity at which the mutants could still survive for at least $24 \mathrm{~h}(250 \mu \mathrm{mol}$ photons $\mathrm{m}^{-2} \mathrm{~s}^{-1}$ ) and which thus corresponds to HL conditions. Indeed, a much stronger stimulation of GPXH expression compared to wild-type could be detected in more

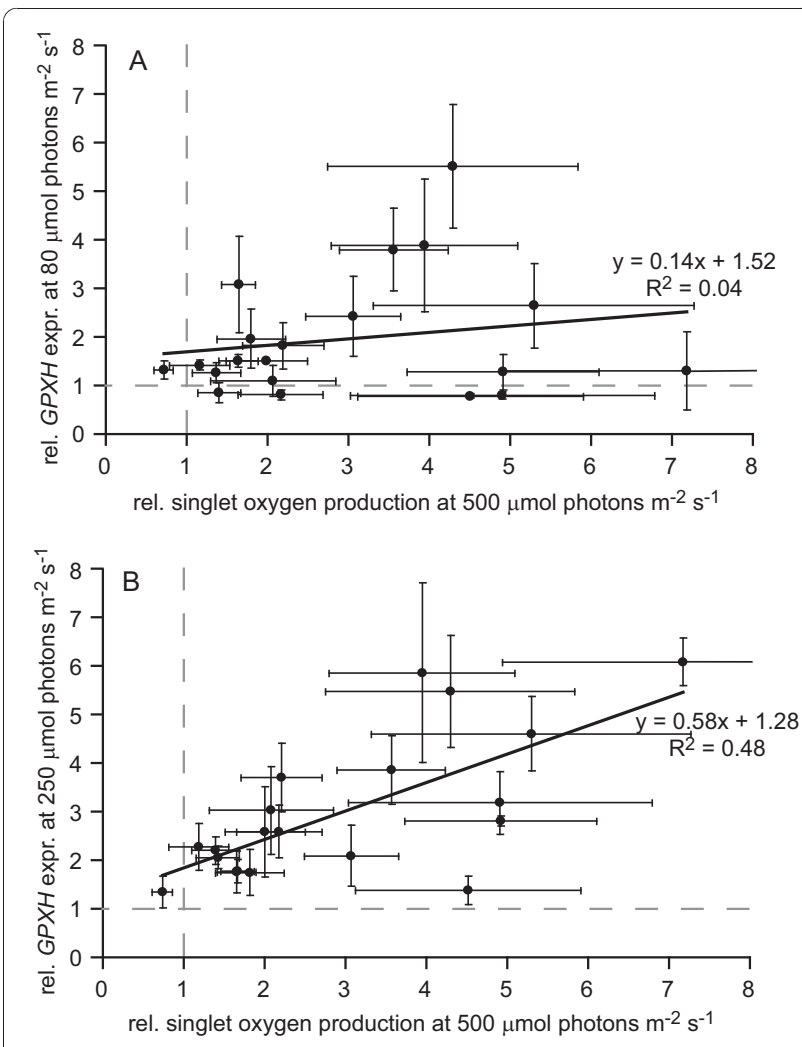

Figure 3 Correlation of ${ }^{1} \mathrm{O}_{2}$ production and GPXH expression Singlet oxygen production was measured with SOSG in each of the 20 gox mutants during short-term exposure to $\mathrm{HL}(500 \mu \mathrm{mol}$ photons $\mathrm{m}^{-2} \mathrm{~s}^{-1}$ for $15 \mathrm{~min}$ ), and was plotted against GPXH expression of the corresponding mutant grown either under $(\mathbf{A})$ ML- $\left(80 \mu \mathrm{mol}\right.$ photons $\left.\mathrm{m}^{-2} \mathrm{~s}^{-1}\right)$ or (B) $\mathrm{HL}$-condition $(250 \mu \mathrm{mol}$ photons $\left.\mathrm{m}^{-2} \mathrm{~s}^{-1}\right)$. This revealed that ${ }^{1} \mathrm{O}_{2}$ production in the mutants positively correlates with GPXH expression under HL- $\left(R^{2}=0.48\right)$ but not ML-conditions $\left(R^{2}=0.04\right)$. The production of ${ }^{1} \mathrm{O}_{2}$ was calculated for each mutant from five and GPXH expression from three independent experiments (average $\pm \mathrm{SE}$ ), and normalized to the corresponding level of the wild-type strain (grey dashed lines). 
than half of the mutants, resulting in a stronger correlation $\left(\mathrm{R}^{2}=0.48\right)$ between ${ }^{1} \mathrm{O}_{2}$ formation and GPXH expression (Figure 3BAdditional file 1).

Increased levels of ${ }^{1} \mathrm{O}_{2}$ in gox mutants are a consequence of either increased generation or lowered detoxification of ${ }^{1} \mathrm{O}_{2}$. The former might result from a deficient photoprotection mechanism, such as a reduced capacity of NPQ. Therefore, NPQ was measured in the gox mutants acclimated to either LL $(15 \mu \mathrm{mol}$ photons $\left.\mathrm{m}^{-2} \mathrm{~s}^{-1}\right)$ or HL $\left(250 \mu \mathrm{mol}\right.$ photons $\left.\mathrm{m}^{-2} \mathrm{~s}^{-1}\right)$ for at least 24 h. Four mutants (22D1, 18C2, 14A9 and 21B4) had significantly reduced NPQ under both LL and HL conditions (Figure 4A). Four other strains (15B10, 18G9, 14B5 and 14C11) only had lower NPQ under HL but not LL conditions, suggesting a light intensity dependent effect, and for three mutants (18F6, 14H8 and 18G9) a stimulation of NPQ even at LL conditions was found.

Energy-dependent quenching ( $\mathrm{qE}$ ) is one component of NPQ that requires synthesis of the xanthophylls, zeaxathin and antheraxanthin. However, these and other carotenoids as well as $\alpha$-tocopherol are also important antioxidants involved in detoxification of ${ }^{1} \mathrm{O}_{2}$. Pigment analysis of the 20 gox mutants acclimated to the same LL or HL intensity as for NPQ measurements revealed only small changes in pigment contents of few strains. Lutein was not altered in LL and only slightly higher in three mutants in HL conditions compared to the wildtype strain (Figure 4C). Similarly, $\alpha$-tocopherol was not strongly affected in LL condition, except for $14 \mathrm{H} 8$, but was significantly reduced in 7 mutants after exposure to HL for $24 \mathrm{~h}$ (Figure 4D). For only one strain, 18F6, higher levels of $\alpha$-tocopherol than in wild-type were detected under HL conditions, and this correlated with increased lutein and zeaxanthin levels in this mutant. Despite the important role of zeaxanthin and antheraxanthin in photoprotection and prevention of ${ }^{1} \mathrm{O}_{2}$ generation, only moderate changes of these xanthophylls were detected in the mutants compared to the wild-type. Only one mutant (18G9) had a significantly reduced deepoxidation of xanthophylls during HL exposure showing that this process seems still to be functional in all mutants (Figure 4B). Nevertheless, when grown in LL, five mutants had significantly reduced de-epoxidation states whereas other mutants had rather increased levels of zeaxanthin and antheraxanthin (Figure 4B and 5B).

\section{GPXH expression and singlet oxygen production negatively correlate with the xanthophyll de-epoxidation state}

In order to analyze the relationship of all the parameters measured in the 20 gox mutants, linear correlation factors were calculated for every possible combination of parameters (Figure 5A). Not surprisingly, a strong positive correlation between antheraxanthin and zeaxanthin levels was found, which negatively correlated with violaxanthin under HL conditions, as expected from operation of the xanthophyll cycle. As already shown in Figure $3 \mathrm{~B},{ }^{1} \mathrm{O}_{2}$ formation correlated with GPXH expression under HL conditions. Both parameters also negatively correlated with antheraxanthin and zeaxanthin levels, especially in LL-grown cultures. Thus, when comparing ${ }^{1} \mathrm{O}_{2}$ production at HL and xanthophyll levels at LL it was striking that all the mutants but one (14C11) had a high de-epoxidation state of xanthophylls or increased ${ }^{1} \mathrm{O}_{2}$ production compared to wild-type (Figure $5 \mathrm{~B})$. This effect was less pronounced when ${ }^{1} \mathrm{O}_{2}$ production was compared with de-epoxidation at HL because strongly stimulated de-epoxidation reduced the relative differences between the clones. Finally, antheraxanthin and zeaxanthin levels of HL-grown cultures weakly correlated with $\alpha$-tocopherol and lutein contents under this light condition.

Hierachical clustering of the mutants with all measured parameters was performed to test whether there are groups of mutants with similar phenotypic pattern. These analyses revealed that one mutant (14H8) behaved differently from all other mutants (Figure 5C). Even though $14 \mathrm{H} 8$ was originally screened for high GPXH-ARS expression and was found to be HL sensitive, it did not show any stimulated GPXH expression or ${ }^{1} \mathrm{O}_{2}$ production at $\mathrm{HL}$ intensities. All other mutants were divided into two major groups (I and II) mainly based on the de-epoxidation state of the xanthophyll pool. Group I had lower levels of antheraxanthin and zeaxanthin at LL than wild-type and most of these mutants showed high ${ }^{1} \mathrm{O}_{2}$ production and increased GPXH expression. They could be further subdivided into two groups, where strain 18F6 and 18G9 belonged to one group (IB) with stimulated NPQ in LL conditions and no changes in $\alpha$-tocopherol levels under any light intensity. Mutants of the other subgroup (IA), on the other hand, had strongly reduced $\alpha$-tocopherol levels, especially in HL grown cultures, and either lowered or not changed NPQ compared to the wild-type strain.

The second group of mutants (II) with similar or slightly increased xanthophyll levels to wild-type had generally a much lower stimulation of ${ }^{1} \mathrm{O}_{2}$ production and GPXH expression than mutants of group I. Exceptions were clones $14 \mathrm{~A} 9$ and 21B4 from subgroup IIA with strong GPXH overexpression and stimulated ${ }^{1} \mathrm{O}_{2}$ production, but these mutants showed strongly reduced NPQ under both LL and HL intensity that was probably responsible for these phenotypes. In the other subgroup (IIB) only two mutants (35H11 and 15B10) had significant GPXH overexpression and higher ${ }^{1} \mathrm{O}_{2}$ production and except for lower $\alpha$-tocopherol levels in HL for some mutants, little differences compared to wild-type were detected for most parameters. 


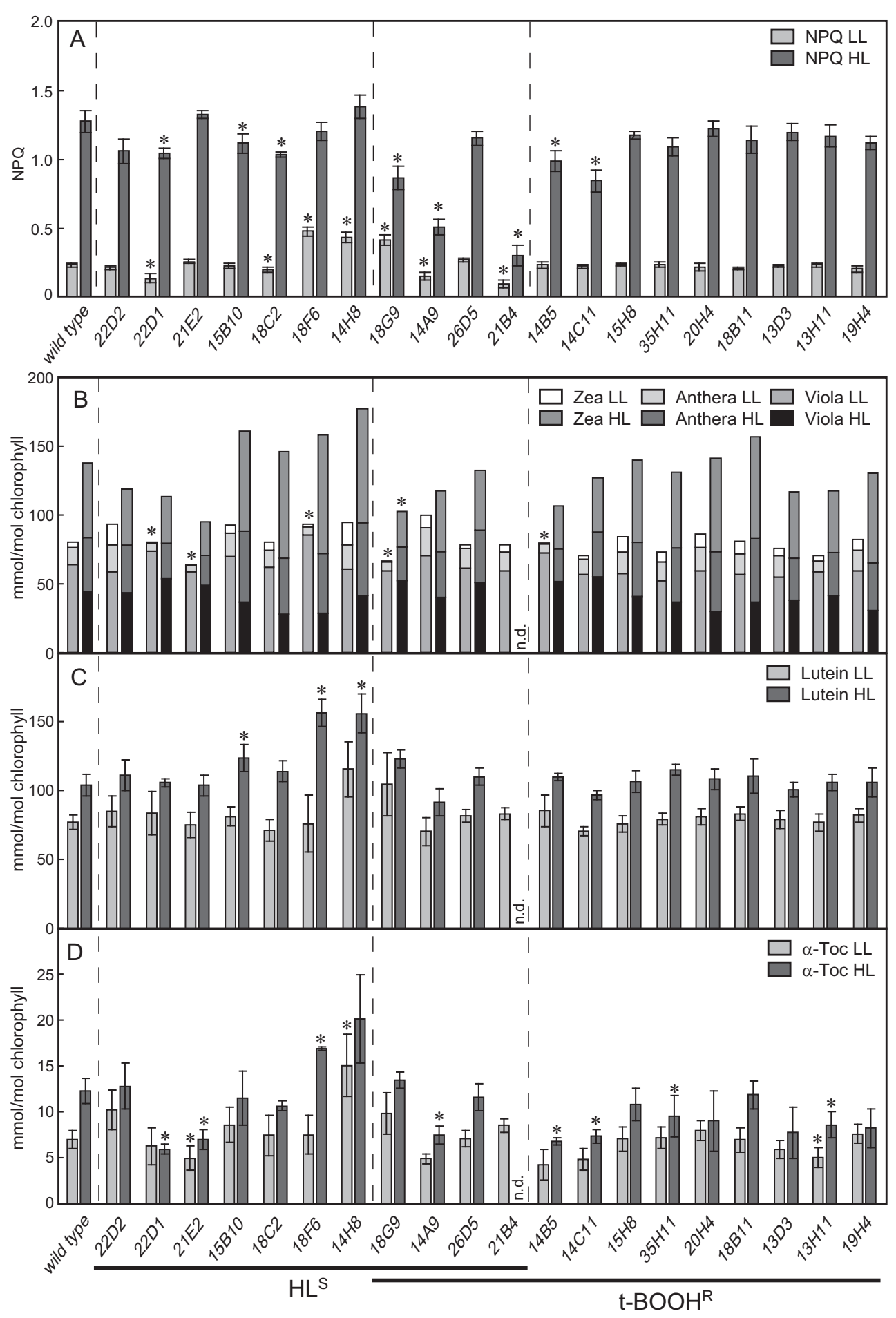

Figure 4 Carotenoid content and NPQ in the isolated gox mutants. Non-photochemical quenching of chlorophyll fluorescence (NPQ) (A), carotenoid contents (B-C), and $\boldsymbol{\alpha}$-tocopherol content (D) of 20 gox mutants were analyzed in cultures grown either under LL (15 $\mu$ mol photons $\left.\mathrm{m}^{-2} \mathrm{~s}^{-1}\right)$ or $\mathrm{HL}$ conditions $\left(250 \mu \mathrm{mol}\right.$ photons $\left.\mathrm{m}^{-2} \mathrm{~s}^{-1}\right)$. The order of clones is the same as in Table 1, divided into $\mathrm{HL}$ sensitive and t-BOOH resistant mutants (n.d.: not determined). Data show averages from 4-5 independent experiments $( \pm \mathrm{SE})$, and significant $(P<0.05)$ differences from wild-type are indicated by a star (in $\mathbf{B}$ significance of deepoxidation of xanthophylls $([Z+A] /[Z+A+V])$ is shown). 


\section{Discussion}

\section{No mutants with deficient GPXH induction}

Screening for mutants with altered GPXH expression resulted in the isolation of several high GPXH expression mutants but no strain with deficient or strongly reduced $G P X H$ induction by ${ }^{1} \mathrm{O}_{2}$ could be isolated. With a total number of $5500 \mathrm{UV}$-mutagenized clones tested we assume that the coverage of mutations in the genome should be high enough to hit at least one component of a putative ${ }^{1} \mathrm{O}_{2}$ signaling cascade with a lossof-function mutation. The relatively high UV dose resulting in the survival of only 0.4 to $2 \%$ of the cells and the fact that during segregation analyses at least two out of five gox mutants contained two mutations affecting the phenotype suggested a high mutation density in the screened population. Still, a second mutant screen for suppressor mutants of GPXH overexpression in strain 21B4 was performed using an additional plasmid containing the GPXH promoter in front of the nitrate reductase gene (data not shown). This enabled a direct selection for reduced expression under low light conditions by selecting for chlorate-sensitive clones. Out of a total number of $2 \times 10^{6}$ cells surviving UV mutagenesis, 1060 clones were chlorate resistant, and of those, 15 clones also had low induction $(<2$ fold) of the GPXH-ARS reporter construct by NR. However, all of these clones showed normal induction of the wild-type GPXH gene, indicating that under these screening conditions no gid mutants can be isolated. The conclusion that in strain $21 \mathrm{~B} 4$ a constant increased ${ }^{1} \mathrm{O}_{2}$ production is responsible for high GPXH expression might explain why no GPXH induction deficient mutants could be isolated, because GPXH might be essential for defense against ${ }^{1} \mathrm{O}_{2}$-induced damage. This can be excluded for the original mutant screen because selection against light-sensitive mutants during the recovery phase after mutagenesis was prevented by growing the 5500 clones in the dark. Furthermore, none of the clones was light sensitive under ML conditions during the induction tests. Thus, even though steps were taken to minimize a negative selection against gid mutants, we cannot exclude that a functional ${ }^{1} \mathrm{O}_{2}$ response of the GPXH and maybe other genes is essential for $C$. reinhardtii. On the other hand, it is also possible that several redundant signaling pathways form a complex network to activate GPXH expression, thereby hampering the isolation of gid mutants. Finally, it still might be that more dark-grown mutagenized clones had to be tested to find the desired mutants. A similar screen to isolate ${ }^{1} \mathrm{O}_{2}$ responsive mutants in $A$. thaliana resulted in the identification of at least three mutants deficient in the upregulation of different ${ }^{1} \mathrm{O}_{2}$-induced genes in the conditional flu mutant [27]. However, ${ }^{1} \mathrm{O}_{2}$-signaling seems to have different cellular functions in A. thaliana, at least in seedlings, where it is part of a programmed cell death response and in $C$. reinhardtii where it seems to be involved in response to cytotoxic environmental stresses [20,28].

\section{GPXH overexpression and correlation with singlet oxygen production, NPQ and pigment levels}

In contrast to the lack of gid mutants, many gox mutants with a stimulated expression of the GPXH wild-type gene, especially under HL intensities, could be isolated (Figure 3). The light intensity-dependent increase of GPXH overexpression and the sensitivity to $\mathrm{HL}$ conditions indicated that in several mutants ${ }^{1} \mathrm{O}_{2}$ formation might be enhanced and cause a photooxidative stress. Indeed, increased ${ }^{1} \mathrm{O}_{2}$ formation was measured in all but one HL-sensitive as well as many HL-resistant gox mutants (Additional file 2), which nicely correlated with GPXH expression under HL conditions (Figure 3B). This indicates that in most or even all gox mutants, GPXH overexpression seems not to be caused by a constitutively active signal transduction pathway but by the increased production of ${ }^{1} \mathrm{O}_{2}$ under the light conditions tested. The poor correlation between ${ }^{1} \mathrm{O}_{2}$ production and GPXH expression under ML (Figure 3A), the clustering in at least five phenotypic distinct groups (Figure $5 \mathrm{C}$ ) and the fact that three of the mutants (18F6, 21B4 and 35H11) have been mapped to different linkage groups (data not shown) indicates that mutations in different nuclear genes are responsible for the increased ${ }^{1} \mathrm{O}_{2}$ production in the various mutants.

Singlet oxygen formation in photosynthetic organisms is caused by the conversion of excited chlorophylls into the triplet state and the reaction with molecular oxygen [3]. The organisms try to minimize this process by regulating the excitation pressure on the PSII reaction center chlorophylls, optimizing the electron flow in the photosynthetic electron transport chain and quenching chlorophyll triplet states and ${ }^{1} \mathrm{O}_{2}$. Thus, ${ }^{1} \mathrm{O}_{2}$ accumulation can result from either stimulated production, e.g. due to enhanced triplet chlorophyll formation, or lowered detoxification of the ROS due to defects in some lightinduced protection mechanisms. Such a defect in protection mechanisms could be the reason for high ${ }^{1} \mathrm{O}_{2}$ formation in most of the group I mutants of cluster analysis (Figure 5C) having reduced zeaxanthin and antheraxanthin levels which correlates with high ${ }^{1} \mathrm{O}_{2}$ formation (Figure 5B). A well characterized mutants with reduced xanthophyll levels and defects in photoprotection is the npq1 lor1 double mutant lacking the carotenoids zeaxanthin, antheraxanthin and lutein. Similar to many mutants of group I, this mutant exhibits increased ROS production, GPXH expression and sensitivity upon HL 


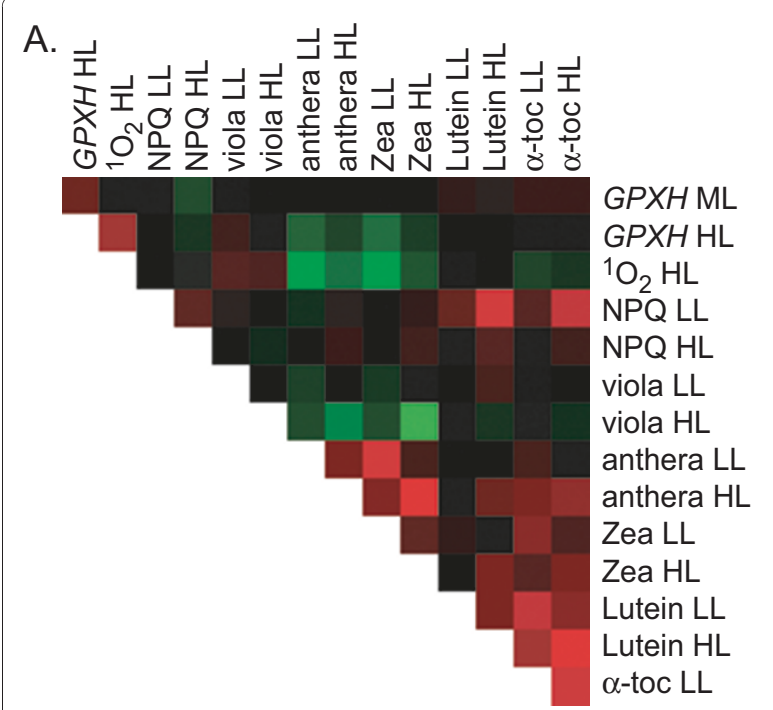

C.

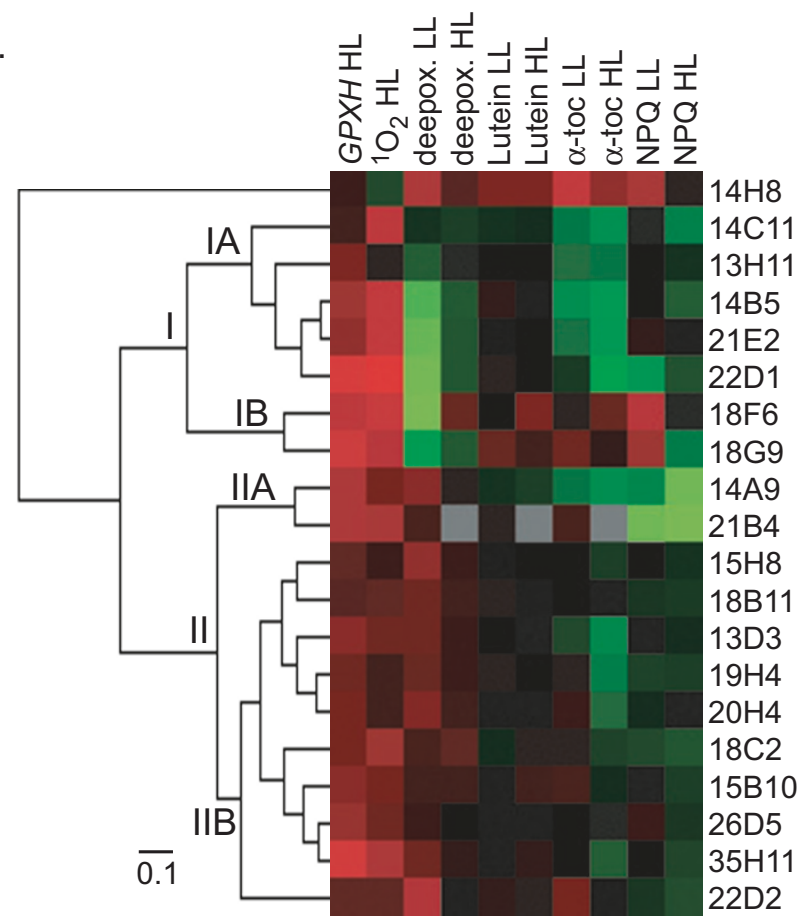

B.

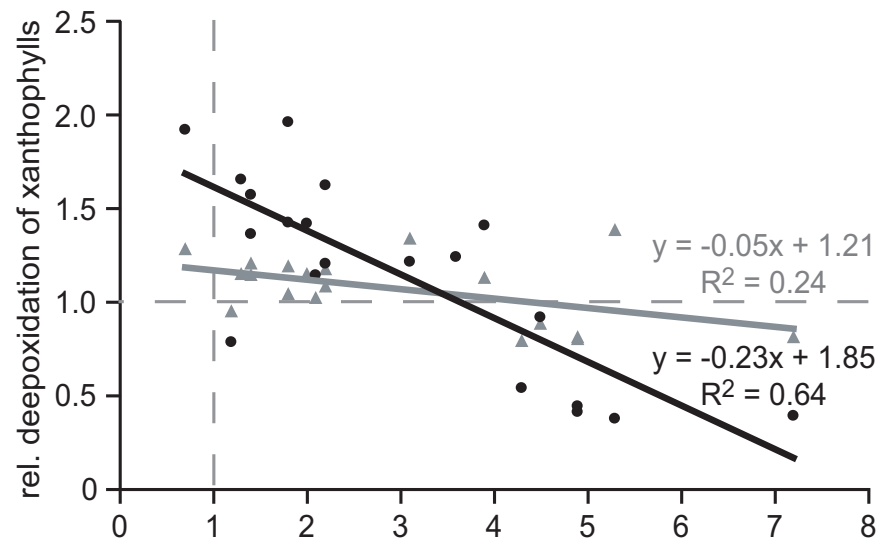

rel. singlet oxygen production at $500 \mu \mathrm{mol}$ photons $\mathrm{m}^{-2} \mathrm{~s}^{-1}$

Figure 5 Correlation of various analyzed parameters in the isolated gox mutants. A. The linear correlation coefficient $R^{2}$ between each combination of the parameter tested in the 20 gox mutants was calculated and values were translated into a color code according the scale indicated. B. The correlation between ${ }^{1} \mathrm{O}_{2}$ production at $\mathrm{HL}$ and deepoxidation of xanthophylls $([\mathrm{Z}+\mathrm{A}] /[\mathrm{Z}+\mathrm{A}+\mathrm{V}])$ at $\mathrm{LL}$ (black circles) and HL (grey triangles) is shown. C. Cluster analysis of 20 gox mutants based on GPXH expression, ${ }^{1} \mathrm{O}_{2}$ production, $\mathrm{NPQ}$ and pigment contents under either $\mathrm{LL}$ or $\mathrm{HL}$ condition as shown in Figure 3 and 4 . All data are relative to wild-type levels under the same growth condition and shown in a color code according the scale indicated. The nature of different groups of mutants is discussed in the text.

but not LL illumination $[16,29]$. However, comparison of $n p q 1$ and npq1 lor 1 showed that reduced levels of zeaxanthin and antheraxanthin but normal levels of other carotenoids like lutein would probably not cause a very strong phenotype $[16,30]$. Thus, reduced efficiency of more than one protection mechanism might be required to achieve increased ${ }^{1} \mathrm{O}_{2}$ accumulation. Indeed, five of the group I mutants with reduced xanthophyll levels (13H11, 14B5, 14C11, 21E2, 22D1) also showed lowered $\alpha$-tocopherol levels under LL and/or HL conditions (Figure 5C, group IA). Furthermore, levels of other components of the thylakoid membrane with ${ }^{1} \mathrm{O}_{2}$-quenching 
capacity like plastoquinone and $\alpha$-tocopherolquinone $[31,32]$ were not quantified but might also be affected in some of the mutants. Thus, reduced photoprotection by the combination of lower xanthophylls, $\alpha$-tocopherol and maybe other deficiencies might be the cause for increased ${ }^{1} \mathrm{O}_{2}$ production and GPXH expression in these mutants. This could either result from mutations in multiple loci, as found for clone 22D1 (Figure 3), or caused by mutations in a single gene encoding for a global regulator of cellular photoprotection mechanisms.

Even though deepoxidation of xanthophylls is involved in NPQ [33], these parameters did not correlate in our mutants $\left(R^{2}<0.01\right)$ indicating that other factors also play an important role for NPQ. For example, two strains of group I (18F6 and 18G9) showed rather increased NPQ levels under LL conditions even though their xanthophyll levels were reduced, clustering them in a separate subgroup (IB) of group I (Figure 5C). Very high GPXH expression in 18F6 and 18G9 under ML conditions indicates stimulated ${ }^{1} \mathrm{O}_{2}$ generation already at LL. We speculate that these mutants might have increased ${ }^{1} \mathrm{O}_{2}$ production due to an enhanced energy transfer from the PSII reaction center to molecular oxygen. By this, quenching of excitation energy by molecular oxygen would increase NPQ but reduce the photosynthetic electron transport rate required for building up the proton gradient and activating the xanthophyll cycle. Thus, reduced xanthophylls would not be the cause but the consequence of increased ${ }^{1} \mathrm{O}_{2}$ production. However, other effects of the mutations cannot be excluded which might also explain these phenotypes.

Contrary to $18 \mathrm{~F} 6$ and $18 \mathrm{G} 9$, two mutants (14A9 and 21B4 in group IIA) had strongly reduced NPQ both under LL and HL conditions but similar or rather increased xanthophyll levels compared to wild-type showing that defects in $\mathrm{qE}$-independent mechanisms seem to affect NPQ in these mutants. Photoinhibition (qI) stimulated by excess light should not be relevant under LL conditions, and a deficiency in state transition (qT) should not strongly affect NPQ at HL intensities. On the other hand, a qE-independent effect was also found in a $C$. reinhardtii mutant defective in two linked LHCSR3 genes [10]. However, segregation analysis of backcrosses of $14 \mathrm{~A} 9$ and 21B4 with a wild-type strain revealed that both mutants have probably mutations in two different genes affecting GPXH expression (Figure 2) indicating that the phenotypes of these mutants could be caused by the combination of different defects.

In mutants with functional detoxification mechanisms, strong ${ }^{1} \mathrm{O}_{2}$ accumulation after stimulated production of the ROS might be prevented by the induction of these detoxification mechanisms. This is supported by the negative correlation of ${ }^{1} \mathrm{O}_{2}$ formation and deepoxidation of xanthophylls, where increased levels of zeaxanthin and antheraxanthin correlate with a low stimulation of ${ }^{1} \mathrm{O}_{2}$ production (Figure 5B). Mutants with increased xanthophyll levels are mainly represented in the group IIB mutants of cluster analysis with rather few and weak phenotypic changes (Figure 5C). A general increase in antioxidant levels including zeaxanthin, antheraxanthin, lutein and $\alpha$-tocopherol and a significant rise in NPQ was detected in strain $14 \mathrm{H} 8$, where no stimulated ${ }^{1} \mathrm{O}_{2}$ production and GPXH expression could be measured any more. This shows that the various protection mechanisms can compensate each other and thus control the production of deleterious ROS. This is in agreement with data of various mutants lacking specific antioxidants: $\alpha$-tocopherol-deficient strains of C. reinhardtii, Synechocystis sp. PCC6803 and A. thaliana all were very tolerant to photooxidative stress during $\mathrm{HL}$ conditions, and only under extreme conditions such as a combination of very HL and low temperature or chemical treatment a phenotype became visible [34-37]. It was suggested that the presence of other antioxidants such as zeaxanthin or increased levels of $\beta$-tocopherol can compensate for $\alpha$-tocopherol deficiency [35,37]. Conversely, the $A$. thaliana npq1 mutant, lacking zeaxanthin and antheraxanthin, accumulates higher amounts of $\alpha$-tocopherol [38]. Thus, zeaxanthin, $\alpha$-tocopherol and plastoquinol have overlapping functions in photoprotection and together prevent the formation of deleterious ${ }^{1} \mathrm{O}_{2}$ under natural conditions [8,32,39-42]. However, when these protection mechanisms are overwhelmed, ${ }^{1} \mathrm{O}_{2}$ starts to accumulate and damage cellular components. This is when defense genes like GPXH, which repair and remove damaged biomolecules, are required to survive the oxidative stress. Activation of genetic stress response without altering antioxidant levels by an acclimation to increased ${ }^{1} \mathrm{O}_{2}$ production or the direct overexpression of the GPXH gene in C. reinhardtii were shown to increased resistance to oxidative stress by $\mathrm{RB}, \mathrm{NR}$ and $\mathrm{t}-\mathrm{BOOH}[20,25]$. Increased tolerance against $\mathrm{t}-\mathrm{BOOH}$ was also found for 13 of the 32 gox mutants tested including all the group IIB mutants as well as strains 14B5, 14C11 and 35H11 (Table 1). Thus, increased expression of stress response genes like GPXH might explain the HL resistance of these mutants and shows the important role of GPXH and other defense genes in the photooxidative stress response of photosynthetic organisms.

\section{Conclusions}

The failure to isolate ${ }^{1} \mathrm{O}_{2}$ signal transduction mutants indicates that several redundant signaling pathways might be involved in the GPXH response. This is supported by the identification of multiple regulatory elements in the GPXH promoter being required for induction of the gene 
[21]. Singlet oxygen generation, on the other hand, was altered in several mutants resulting in higher expression of the GPXH gene. Increased oxidative stress resistance of many of these mutants confirms the importance of the ${ }^{1} \mathrm{O}_{2}$-induced genetic response in the defense against ROSinduced damage. Furthermore, isolation of phenotypic different groups of ${ }^{1} \mathrm{O}_{2}$-overproducing mutants indicates that mutations in different photoprotective mechanisms might be responsible for higher ${ }^{1} \mathrm{O}_{2}$ levels in various gox mutants which most seem to be, based on pigment analysis, different from known photoprotective mutants like npq1 lor1. The comparison of their phenotypes suggests that in several gox mutants multiple defense processes might be affected what might be due to, among other things, mutations in a global regulator of cellular photoprotection mechanisms. Thus, the isolation of these mutants might allow identifying new components involved in the control of ${ }^{1} \mathrm{O}_{2}$ formation by different cellular protection mechanisms.

\section{Methods}

\section{Strains and growth conditions}

The $C$. reinhardtii strain used to generate the population of mutants was $4 \mathrm{~A}^{+}$pYSn 1 , which is in a $137 \mathrm{c}$ (CC-125) background [43]. This strain was generated by co-transformation of $4 \mathrm{~A}^{+}$with the plasmids pYSn1 containing the GPXH-arylsulfatase reporter construct [21] and $\mathrm{pBC} 1$ containing the Streptomyces aminoglycoside 3'-phosphotransferase typeVIII encoding gene (aphVIII) for selection of transformants on paromomycin [44]. A near-isogenic $\mathrm{mt}^{-}$strain $\left(4 \mathrm{~A}^{-} \mathrm{pYSn} 1\right)$ was obtained by crossing $4 \mathrm{~A}^{+}$pYS1 with $4 \mathrm{~A}^{-}$[43] and used to backcross mutants for segregation analysis.

All strains were grown heterotrophically in Tris-AcetatePhosphate-medium (TAP) [45] either on 1.5\% agar plates or in liquid cultures agitated on a rotary shaker (120 rpm) at $22^{\circ} \mathrm{C}$ and the light conditions indicated. For storage, mutants were kept on TAP agar plates in dim light.

\section{Screening for GPXH expression mutants}

UV mutagenesis was performed in an UV Stratalin$\mathrm{ker}^{\mathrm{rn}} 1800$ (Stratagene, CA). Cells were grown heterotrophically to a density of $5 \times 10^{6}$ cells ml $^{-1}$, and $20 \mathrm{ml}$ were aliquoted into a sterile Pyrex ${ }^{\oplus}$ petri dish $(14 \mathrm{~cm}$ diameter)

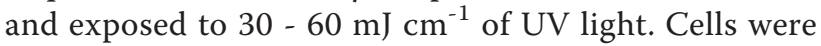
kept in the dark for 1 day immediately following UV treatment to prevent initiation of light-activated DNA repair mechanisms. Then the UV-mutagenized cells were spread on TAP plates and incubated in the dark until colonies appeared.

A total of 5500 colonies were picked, transferred onto fresh TAP plates and maintained at low light (LL, 15 $\mu \mathrm{mol}$ photons $\mathrm{m}^{-2} \mathrm{~s}^{-1}$ ) for 5 to 10 days. These clones were used to inoculate $150 \mu \mathrm{l}$ TAP in 96-well plates by replica plating. After 2 days of growth at medium light (ML, $80 \mu \mathrm{mol}$ photons $\mathrm{m}^{-2} \mathrm{~s}^{-1}$ ), another $150 \mu \mathrm{l}$ of TAP was added to the cultures, mixed and divided into two separate 96-well plates. To induce GPXH expression, NR $(1 \mu \mathrm{M})$ was added to one of the plates and incubated at ML for 8 hours. Arylsulfatase activity was analyzed by adding $7.5 \mu \mathrm{l}$ of a $20 \times$ GIN solution $(1 \mathrm{M}$ glycine- $\mathrm{NaOH} \mathrm{pH}$ 9.0, 0.4 $\mathrm{M}$ imidazole, and $180 \mathrm{mM}$ $p$-nitrophenylsulfate) and measuring absorbance at $410 \mathrm{~nm}$ after $0,5,10$ and $20 \mathrm{~min}$ of incubation at $35^{\circ} \mathrm{C}$. In parallel, absorbance at $750 \mathrm{~nm}$ was measured to determine cell density and normalized ARS activity was calculated with the following equation:

$$
\text { ARS activity }=\left(\text { slope }\left(\mathrm{OD}_{410}-\mathrm{OD}_{750} ; \mathrm{t}\right)\right) / \mathrm{OD}_{750}
$$

Relative GPXH-ARS expression was then calculated for each clone by dividing its ARS activity by the average control ARS activity. After the initial selection for altered $A R S$ expression, the clones were rescreened three more times under the same exposure conditions to ensure reproducible changes in the selected mutants.

\section{Testing for resistance phenotypes}

Resistance to different oxidative stress conditions was tested by inoculating the clones in $150 \mu \mathrm{TAP}$ in a 96-well plate and incubation at ML for 2 days. Then $5 \mu$ of each cultures was spotted on TAP plates containing the following chemicals: tert-butylhydroperoxide (t-BOOH: 100 , 150, 200 and $250 \mu \mathrm{M}$ ), neutral red (NR: 4, 5, 8, 12 and $18 \mu \mathrm{M}$ ), rose bengal (RB: 2, 2.5, 3, 4 and $5 \mu \mathrm{M}$ ), metronidazole (MZ: 1, 2, 3, 5 and $8 \mathrm{mM}$ ), methyl viologen (MV: $0.5,1,1.5,2$ and $3 \mu \mathrm{M})$. The plates were incubated at either LL (t-BOOH, MZ and MV) or ML (NR and RB), together with a control plate without any chemical for 3 to 4 days depending on the light intensity. High light resistance was tested by exposing $5 \mu \mathrm{l}$ of cultures on a TAP plate to $500 \mu \mathrm{mol}$ photons $\mathrm{m}^{-2} \mathrm{~s}^{-1}$ (HL) for 3 days.

\section{Segregation analysis}

Six mutants (14A9, 18F6, 18G9, 21B4, 22D1 and 35H11) were analyzed genetically for segregation of their phenotypes by crossing them to strain $4 \mathrm{~A}^{-}$pYS1. The resulting zygospores were harvested and dissected as described in Harris (1989). For each mutant a total of twelve tetrads with four surviving cells each were analyzed for their GPXH-ARS expression pattern except for 18G9, which did not result in any viable progenies. GPXH-ARS expression analysis was performed as described above in three replicates per clone.

\section{Singlet oxygen formation}

Cultures grown under LL to $3 \times 10^{6}$ cells $\mathrm{ml}^{-1}$ were adjusted to $3 \mu \mathrm{g} \mathrm{ml}^{-1}$ chlorophyll content, and $0.5 \mathrm{ml}$ 
samples were frozen in liquid nitrogen to lyse the cells. After thawing, $100 \mu \mathrm{l}$ of cell suspension were transferred to a black 96-well plate. To all the samples including two medium-only controls for background correction, $1 \mu \mathrm{l}$ of a $1 \mathrm{mM}$ Singlet Oxygen Sensor Green (SOSG) (Invitrogen/Molecular Probes) solution was added. Fluorescence levels were measured as peak height at $530 \mathrm{~nm}$ (excitation $480 \mathrm{~nm}$ ) [26] after 0 and $15 \mathrm{~min}$ of exposure to $\mathrm{HL}$ conditions $\left(500 \mu \mathrm{mol}\right.$ photons $\left.\mathrm{m}^{-2} \mathrm{~s}^{-1}\right)$ in a Tecan infinite 200 fluorescence plate reader. To confirm ${ }^{1} \mathrm{O}_{2}$ detection by SOSG, fluorescence spectra of cultures exposed to the same light conditions in the presence of either $10 \mathrm{mM}$ of the ${ }^{1} \mathrm{O}_{2}$ quencher 1,4-diazabicyclo[2.2.2] octane (DABCO) or in medium containing $50 \%$ deuterium oxide $\left(\mathrm{D}_{2} \mathrm{O}\right)$ were measured representatively for strain 22D1 in three independent replicates (Additional file 3). As expected, DABCO reduced the fluorescence signal of SOSG by quenching ${ }^{1} \mathrm{O}_{2}$ whereas $\mathrm{D}_{2} \mathrm{O}$ stimulated the signal because $\mathrm{D}_{2} \mathrm{O}$ increases the ${ }^{1} \mathrm{O}_{2}$ lifetime. Furthermore, no increased SOSG fluorescence could be measured in dark incubated algal samples compared to medium-only controls (background) confirming the detection of ${ }^{1} \mathrm{O}_{2}$ by SOSG. Singlet oxygen production for each strain was determined by calculating the slope of the increase in background-corrected SOSG fluorescent signals during the $15 \mathrm{~min}$ of exposure, and relative values were calculated for each mutant by dividing its levels by the levels of ${ }^{1} \mathrm{O}_{2}$ production in the wild-type strain.

\section{RNA isolation and quantitative real-time PCR (qPCR)}

Cells of $5 \mathrm{ml}$ cultures grown to $3 \times 10^{6}$ cells ml$^{-1}$ at the light condition indicated were harvested by centrifugation. Total RNA was isolated by the Trizol method as described earlier [46]. For qPCR experiments, $200 \mathrm{ng}$ of individual total RNA was used in each $10 \mu$ l reverse transcription reaction with a reverse transcription kit (Applied Biosystems) according to the manufacturer's instruction.

Sequences of primers for qPCR were designed with the Primer Express ${ }^{\mathrm{Tt}}$ software (Applied Biosystems). qPCR reactions were performed on the ABI Prism 7000 or 7500 Sequence Detection System (Applied Biosystems) as described earlier [46]. Threshold cycle $\left(C_{t}\right)$ values were determined for all reactions in the logarithmic amplification phase, and the average $C_{t}$ value was calculated for each sample out of three technical replicates. Each reaction was confirmed to contain a single amplicon by gel electrophoresis and melting curves. Genomic DNA contamination in RNA samples was assessed by qPCR using RNA without reverse transcription as templates, and in all cases had at least six $\mathrm{C}_{\mathrm{t}^{-}}$ values higher than that of respective cDNAs. The efficiency for the amplification of each product was determined by serial dilutions of template cDNA and used to correct $C_{t}$ values for variable amplification efficiencies. The $\mathrm{C}_{\mathrm{t}}$ values of the $C B L P$ gene were used as the internal references. Relative expression was calculated for each mutant compared to $4 \mathrm{~A}^{+}$pYS1 under the same growth conditions as an average with standard error out of three independent experiments.

\section{Pigment analyses}

For tocopherol and pigment analysis, cells from $1 \mathrm{ml}$ samples were harvested by centrifugation and immediately frozen in liquid nitrogen. Pigments and $\alpha$-tocopherol were extracted by vortexing in $300 \mu \mathrm{l}$ of acetone for $1 \mathrm{~min}$, and the extracts were filtered through $2 \mu$ m nylon filters. Pigments were fractionated and analyzed by high-performance liquid chromatography (HPLC) as described previously [42].

\section{Determination of NPQ}

Chlorophyll fluorescence was determined with an imaging pulse amplitude modulated (IPAM) chlorophyll fluorescence system (IMAG-MAX/l, Walz, Germany). Mutants were grown under LL $\left(15 \mu \mathrm{mol}\right.$ photons $\left.\mathrm{m}^{-2} \mathrm{~s}^{-1}\right)$ or $250 \mu \mathrm{mol}$ photons $\mathrm{m}^{-2} \mathrm{~s}^{-1}$ for 2 days up to a density of $3 \times 10^{6}$ cells ml ${ }^{-1}$ before the cells of $200 \mu$ l of culture were collected on a glass microfiber filter (Whatman, UK) by vacuum filtration. To keep filters moist they were transferred on a wet paper towel and cells were dark adapted for 20 min before maximal chlorophyll fluorescence level $F_{m}$ was determined. Then actinic light of the same intensity as growth light was turned on for $15 \mathrm{~min}$ before $F_{m}$ ' was measured to calculate average NPQ as $\left(F_{m}-F_{m}\right) / F_{m}$ ' of five independent replicates.

\section{Cluster analysis}

Hierarchical gene clustering was performed using the Cluster 3.0 software. Data were first log transformed and normalized by multiplying all values of a parameter with a constant scale factor so that the sum of the squares of the values for each parameter was 1.0. This resulted in a scale factor for GPXH expression and ${ }^{1} \mathrm{O}_{2}$ formation of 7.1. For NPQ and pigment contents, which had similar maximal levels, a single scale factor (3.5) was calculated based on the parameter with the highest sum of squares (deepoxidation at LL). Clustering was performed based on average linkage and the results were visualized in a color-based expression pattern using the TreeView 1.60 software designed by the Eisen Lab http://rana.lbl.gov/.

\section{Statistical analysis}

Different parameters determined for individual mutant were analyzed for their significant differences to the same parameters measured in the wild-type strain using 
a paired Student's $t$-test. Significant differences at a $p$-value $<0.05$ are indicated by a star. Correlations of different parameters were analyzed by linear regression and indicated by the square of the corresponding regression coefficient $\left(R^{2}\right)$.

\section{Additional material}

\section{Additional file 1: GPXH-ARS and GPXH expression. \\ Additional file 2: Sensitivity and relative ${ }^{1} \mathrm{O}_{2}$ formation of the various gox mutants.}

Additional file 3: Fluorescence spectra of SOSG. The fluorescence spectra were monitored representatively in samples of strain 22D1 exposed to $\mathrm{HL}$-conditions for 15 min (grey lines) in either normal TAP medium (full line), TAP with $10 \mathrm{mM}$ of the ${ }^{1} \mathrm{O}_{2}$ quencher 1,4-diazabicyclo [2.2.2] octane (DABCO) (dashed line) or medium containing $50 \%$ deuterium oxide $\left(D_{2} O\right)$ (dash-dotted line) which increases the lifetime of ${ }^{1} \mathrm{O}_{2}$. As control, dark incubated samples (black lines) in the presence (full line) or absence of algae (dotted line) (SOSG background) are shown.

\section{Acknowledgements}

We thank Setsuko Wakao for critical reading of the manuscript. This work was supported by a grant from the National Institutes of Health (GM071908) to K.K.N.

\section{Author details}

${ }^{1}$ Department of Plant and Microbial Biology, University of California, Berkeley, CA 94720-3102 USA. Eawag, Swiss Federal Institute of Aquatic Science and Technology, Department of Environmental Toxicology, Ueberlandstrasse 133, $\mathrm{CH}-8600$ Dübendorf, Switzerland.

\section{Authors' contributions}

BBF designed and performed the experiments, evaluated the data and drafted the manuscript. RILE and KKN contributed to conception and design of the experiments, data interpretation and drafting the manuscript. All authors have read and approved the final manuscript.

Received: 9 July 2010 Accepted: 17 December 2010 Published: 17 December 2010

\section{References}

1. Pospíšil P: Production of reactive oxygen species by photosystem II. Biochim Biophys Acta 2009, 1787:1151-1160.

2. Asada K: Production and scavenging of reactive oxygen species in chloroplasts and their functions. Plant Physiol 2006, 141:391-396.

3. Krieger-Liszkay A: Singlet oxygen production in photosynthesis. J Exp Bot 2005, 56:337-346.

4. Triantaphylidès C, Krischke M, Hoeberichts FA, Ksas B, Gresser G, Havaux M, Van Breusegem F, Mueller MJ: Singlet oxygen is the major reactive oxygen species involved in photooxidative damage to plants. Plant Physiol 2008, 148:960-968.

5. Müller $P$, Li XP, Niyogi KK: Non-photochemical quenching. A response to excess light energy. Plant Physiol 2001, 125:1558-1566.

6. Wollman FA: State transitions reveal the dynamics and flexibility of the photosynthetic apparatus. Embo J 2001, 20:3623-3630.

7. Baroli I, Niyogi KK: Molecular genetics of xanthophyll-dependent photoprotection in green algae and plants. Phil Trans $R$ Soc Lond B Biol Sci 2000, 355:1385-1394.

8. Havaux M, Dall'Osto L, Bassi R: Zeaxanthin has enhanced antioxidant capacity with respect to all other xanthophylls in Arabidopsis leaves and functions independent of binding to PSII antennae. Plant Physiol 2007 145:1506-1520.

9. Johnson MP, Havaux M, Triantaphylidès $C$, Ksas B, Pascal AA, Robert B, Davison PA, Ruban AV, Horton P: Elevated zeaxanthin bound to oligomeric LHCII enhances the resistance of Arabidopsis to photooxidative stress by a lipid-protective, antioxidant mechanism. J Biol Chem 2007, 282:22605-22618.

10. Peers G, Truong TB, Ostendorf E, Busch A, Elrad D, Grossman AR, Hippler M, Niyogi KK: An ancient light-harvesting protein is critical for the regulation of algal photosynthesis. Nature 2009, 462:518-U215.

11. op den Camp RG, Przybyla D, Ochsenbein C, Laloi C, Kim C, Danon A, Wagner D, Hideg E, Gobel C, Feussner I, et al: Rapid induction of distinct stress responses after the release of singlet oxygen in Arabidopsis. Plant Cell 2003, 15:2320-2332.

12. Laloi C, Stachowiak M, Pers-Kamczyc E, Warzych E, Murgia I, Apel K: Crosstalk between singlet oxygen- and hydrogen peroxide-dependent signaling of stress responses in Arabidopsis thaliana. Proc Natl Acad Sci USA 2007, 104:672-677.

13. Wagner D, Przybyla D, Op den Camp R, Kim C, Landgraf F, Lee KP, Wursch M, Laloi C, Nater M, Hideg E, et al: The genetic basis of singlet oxygen-induced stress responses of Arabidopsis thaliana. Science 2004 306:1183-1185

14. Lee KP, Kim C, Landgraf F, Apel K: EXECUTER1- and EXECUTER2dependent transfer of stress-related signals from the plastid to the nucleus of Arabidopsis thaliana. Proc Natl Acad Sci USA 2007, 104:10270-10275.

15. Fischer BB, Krieger-Liszkay A, Eggen RIL: Oxitative stress induced by the photosensitizers neutral red (type I) or rose bengal (type II) in the light causes different genetic responses in Chlamydomonas reinhardtii. Plant Sci 2005, 168:747-759.

16. Ledford HK, Baroli I, Shin JW, Fischer BB, Eggen RIL, Niyogi KK: Comparative profiling of lipid-soluble antioxidants and transcripts reveals two phases of photo-oxidative stress in a xanthophyll-deficient mutant of Chlamydomonas reinhardtii. Mol Genet Genomics 2004, 272:470-479.

17. Shao N, Krieger-Liszkay A, Schroda M, Beck CF: A reporter system for the individual detection of hydrogen peroxide and singlet oxygen: its use for the assay of reactive oxygen species produced in vivo. Plant J 2007, 50:475-487.

18. Leisinger U, Rüfenacht $K$, Fischer B, Pesaro M, Spengler A, Zehnder AJB, Eggen RIL: The glutathione peroxidase homologous gene from Chlamydomonas reinhardtii is transcriptionally up-regulated by singlet oxygen. Plant Mol Biol 2001, 46:395-408.

19. Fischer BB, Eggen RIL, Trebst A, Krieger-Liszkay A: The glutathione peroxidase homologous gene Gpxh in Chlamydomonas reinhardtii is upregulated by singlet oxygen produced in photosystem II. Planta 2006, 223:583-590.

20. Fischer BB, Dayer R, Wiesendanger M, Eggen RIL: Independent regulation of the GPXH gene expression by primary and secondary effects of high light stress in Chlamydomonas reinhardtii. Physiol Plant 2007, 130:195-206.

21. Fischer BB, Dayer R, Schwarzenbach $Y$, Lemaire SD, Behra R, Liedtke A, Eggen RIL: Function and regulation of the glutathione peroxidase homologous gene GPXH/GPX5 in Chlamydomonas reinhardtii. Plant Mol Biol 2009, 71:569-583.

22. Girotti AW, Kriska T: Role of lipid hydroperoxides in photo-oxidative stress signaling. Antioxid Redox Signal 2004, 6:301-310

23. Mueller MJ, Berger S: Reactive electrophilic oxylipins: Pattern recognition and signalling. Phytochemistry 2009, 70:1511-1521.

24. Fischer BB, Krieger-Liszkay A, Hideg E, Snyrychova I, Wiesendanger M, Eggen RIL: Role of singlet oxygen in chloroplast to nucleus retrograde signaling in Chlamydomonas reinhardtii. FEBS Lett 2007, 581:5555-5560.

25. Ledford HK, Chin BL, Niyogi KK: Acclimation to singlet oxygen stress in Chlamydomonas reinhardtii. Eukaryot Cell 2007, 6:919-930.

26. Flors C, Fryer MJ, Waring J, Reeder B, Bechtold U, Mullineaux PM, Nonell S, Wilson MT, Baker NR: Imaging the production of singlet oxygen in vivo using a new fluorescent sensor, Singlet Oxygen Sensor Green ${ }^{\oplus}$. J Exp Bot 2006, 57:1725-1734.

27. Baruah A, Simkova K, Apel K, Laloi C: Arabidopsis mutants reveal multiple singlet oxygen signaling pathways involved in stress response and development. Plant Mol Biol 2009, 70:547-563.

28. Kim C, Meskauskiene R, Apel K, Laloi C: No single way to understand singlet oxygen signalling in plants. EMBO Rep 2008, 9:435-439.

29. Baroli I, Gutman BL, Ledford HK, Shin JW, Chin BL, Havaux M, Niyogi KK: Photo-oxidative stress in a xanthophyll-deficient mutant of Chlamydomonas. J Biol Chem 2004, 279:6337-6344

30. Niyogi KK, Björkman O, Grossman AR: The roles of specific xanthophylls in photoprotection. Proc Natl Acad Sci USA 1997, 94:14162-14167. 
31. Gruszka J, Pawlak A, Kruk J: Tocochromanols, plastoquinol, and other biological prenyllipids as singlet oxygen quenchers-determination of singlet oxygen quenching rate constants and oxidation products. Free Radic Biol Med 2008, 45:920-928.

32. Kruk J, Trebst A: Plastoquinol as a singlet oxygen scavenger in photosystem II. Biochim Biophys Acta 2008, 1777:154-162.

33. Demmig-Adams B: Carotenoids and photoprotection in plants - a role for the xanthophyll zeaxanthin. Biochim Biophys Acta 1990, 1020:1-24.

34. Yang Y, Yin C, Li W, Xu X: Alpha-tocopherol is essential for acquired chilllight tolerance in the cyanobacterium Synechocystis sp. strain PCC 6803. J Bacteriol 2008, 190:1554-1560.

35. Havaux M, Eymery F, Porfirova S, Rey P, Dörmann P: Vitamin E protects against photoinhibition and photooxidative stress in Arabidopsis thaliana. Plant Cell 2005, 17:3451-3469.

36. Maeda H, Sakuragi Y, Bryant DA, DellaPenna D: Tocopherols protect Synechocystis sp strain PCC 6803 from lipid peroxidation. Plant Physiol 2005, 138:1422-1435.

37. Sirikhachornkit A, Shin JW, Baroli I, Niyogi KK: Replacement of \{alpha\}tocopherol by \{beta\}-tocopherol enhances resistance to photo-oxidative stress in a xanthophyll-deficient strain of Chlamydomonas reinhardtii. Eukaryot Cell 2009, 8:1648-1657.

38. Havaux M, Bonfils JP, Lütz C, Niyogi KK: Photodamage of the photosynthetic apparatus and its dependence on the leaf developmental stage in the npq1 Arabidopsis mutant deficient in the xanthophyll cycle enzyme violaxanthin de-epoxidase. Plant Physiol 2000 124:273-284

39. Di Mascio P, Devasagayam TP, Kaiser S, Sies H: Carotenoids, tocopherols and thiols as biological singlet molecular oxygen quenchers. Biochem Soc Trans 1990, 18:1054-1056.

40. Trebst A, Depka B, Hollander-Czytko H: A specific role for tocopherol and of chemical singlet oxygen quenchers in the maintenance of photosystem II structure and function in Chlamydomonas reinhardtii. FEBS Lett 2002, 516:156-160.

41. Kruk J, Hollander-Czytko H, Oettmeier W, Trebst A: Tocopherol as singlet oxygen scavenger in photosystem II. J Plant Physiol 2005, 162:749-757.

42. Baroli I, Do AD, Yamane T, Niyogi KK: Zeaxanthin accumulation in the absence of a functional xanthophyll cycle protects Chlamydomonas reinhardtii from photooxidative stress. Plant Cell 2003, 15:992-1008.

43. Dent RM, Haglund CM, Chin BL, Kobayashi MC, Niyogi KK: Functional genomics of eukaryotic photosynthesis using insertional mutagenesis of Chlamydomonas reinhardtii. Plant Physiol 2005, 137:545-556.

44. Sizova IA, Lapina TV, Frolova ON, Alexandrova NN, Akopiants KE Danilenko VN: Stable nuclear transformation of Chlamydomonas reinhardtii with a Streptomyces rimosus gene as the selective marker. Gene 1996, 181:13-18.

45. Harris EH: The Chlamydomonas sourcebook: a comprehensive guide to biology and laboratory use. San Diego: Academic Press; 1989.

46. Fischer BB, Krieger-Liszkay A, Eggen RIL: Photosensitizers neutral red (type I) and rose bengal (type II) cause light-dependent toxicity in Chlamydomonas reinhardtii and induce the Gpxh gene via increased singlet oxygen formation. Environ Sci Technol 2004, 38:6307-6313.

doi:10.1186/1471-2229-10-279

Cite this article as: Fischer et al:: Characterization of singlet oxygenaccumulating mutants isolated in a screen for altered oxidative stress response in Chlamydomonas reinhardtii. BMC Plant Biology 2010 10:279.

\section{Submit your next manuscript to BioMed Central and take full advantage of:}

- Convenient online submission

- Thorough peer review

- No space constraints or color figure charges

- Immediate publication on acceptance

- Inclusion in PubMed, CAS, Scopus and Google Scholar

- Research which is freely available for redistribution

Submit your manuscript at www.biomedcentral.com/submit
Biomed Central 